\title{
Does FDI affect carbon intensity? New evidence from dynamic panel analysis
}

\author{
Yanmin Shao \\ Donlinks School of Economics and Management, \\ University of Science and Technology Beijing, Beijing, China and \\ Academy of Mathematics and Systems Science, Chinese Academy of Sciences, \\ Beijing, China
}

\begin{abstract}
Purpose - This paper aims to clarify the relationship between foreign direct investment (FDI) and carbon intensity. This study uses the dynamic panel data model to study and provide fresh evidence for the issue.

Design/methodology/approach - This study first uses the dynamic panel data model to consider the endogeneity problem, and applies a system-generalized method of moments estimator to study the effect of FDI on carbon intensity using the panel data of 188 countries during 1990-2013.

Findings - The result shows that FDI has a significant negative impact on carbon intensity of the host country. After considering the other factors, including share of fossil fuels, industrial intensity, urbanization level and trade openness, the impact of FDI on carbon intensity is still significantly positive. In addition, FDI also has a significant negative impact on carbon intensity of high-income countries and middle- and lowincome countries.

Originality/value - This paper offers two contributions to the literature on the effect of FDI on carbon intensity. From a methodological perspective, this paper is the first to apply a dynamic panel data model to study the effect of FDI on carbon intensity using worldwide panel data. Second, this paper is the first to analyze the effect of FDI on carbon intensity in different countries with different income levels separately.
\end{abstract}

Keywords Foreign direct investment, Carbon intensity, Pollution halo effect

Paper type Research paper

\section{Introduction}

During the mid-twentieth century, with the development of economic globalization, multinational companies actively participated in international production and operation, which encouraged the moving of resources globally. Multinational companies promote resource optimization worldwide, affect the utilization of natural resources in the host country and influence their emission of pollutants. On the one hand, the change in the layout of multinational companies also might result in a redistribution of carbon emissions in different countries, as it might promote the global spread of capital and technology and

(C) Yanmin Shao. Published by Emerald Publishing Limited. This article is published under the Creative Commons Attribution (CC BY 4.0) licence. Anyone may reproduce, distribute, translate and create derivative works of this article (for both commercial \& non-commercial purposes), subject to full attribution to the original publication and authors. The full terms of this licence may be seen at http://creativecommons.org/licences/by/4.0/legalcode

This research was supported by the National Natural Science Foundation of China (NSFC) under grant nos. 71573251 and 71103177 . 
IJCCSM

10,1

accelerate the speed of technological diffusion (Acharyya, 2009). On the other hand, multinational companies with advanced technology and capital transfer might promote the development of technology in the host country and reduce the emission intensity during the utilization of regional resources. Moreover, the emission efficiency-enhancing technologies, policies and performances found in one economy diffuse ("spillover") into another economy via transnational economic linkages (Hoffmann et al., 2005; Perkins and Neumayer, 2012; Wheeler, 2001). Therefore, foreign direct investment (FDI) might not only promote the transfer of production capacity but also affect the environmental pollutions.

The initial research mainly focused on the economic and social development of the host country. With the concern of environmental issues in the late twentieth century, the impact of FDI on the host country's environment began to attract the attention of scholars. However, at present, there is no consistent conclusion regarding the effect of FDI on the host country's environment.

Some scholars argue that FDI results in pollution havens. Others claim that FDI effectively lessens pollution by allowing a more efficient use of resources and the diffusion of clean technologies. There are three different kinds of viewpoints about the effect of FDI on the environment of the host country. The first kind of viewpoint is that FDI transfers lowcarbon technology, equipment and production processes to the host country to help the country accelerate the development of a low-carbon economy (Gray, 2002; Perkins and Neumayer, 2008; Talukdar and Meisner, 2001; Wheeler, 2001). The second type of viewpoint is that FDI significantly increases the carbon emissions of the host country (Acharyya, 2009; Grimes and Kentor, 2003; Hoffmann et al., 2005; Javorcik and Wei, 2001; Jorgenson, 2007). The third kind of viewpoint is that FDI does not have any significant effect on the carbon emissions of the host country (Kentor and Grimes, 2006; Perkins and Neumayer, 2009). With the increase of global transnational investment and the attention on the environment, the influence of FDI on carbon intensity might be changed because of the diverse motivations of FDI in different countries. Therefore, it is necessary to test the effect of FDI on carbon intensity using recent data.

This paper offers two contributions to the literature on the effect of FDI on carbon intensity. From a methodological perspective, to the best of my knowledge, this paper is the first to apply a system-generalized method of moments (GMM) estimator to study the effect of FDI on carbon intensity using worldwide panel data. In this regard, the study of dynamic specification with a lagged dependent variable has been largely unexplored in the existing literature. As carbon intensity evolves cumulatively over time, current emissions are likely to be linked to those of the past year, rendering it appropriate to consider a dynamic panel data model that includes the lagged dependent variable. In addition, the system GMM is more appropriate in estimating a dynamic panel data model, as it can address the issues of endogeneity, heteroskedasticity and autocorrelation within the related variables. Furthermore, the estimation result is more reliable (Li et al., 2016).

Several studies indicate that the relation between environmental pollution and FDI across different countries and across developed countries might be diverse (Birdsall and Wheeler, 1993), and this study expands the scope of the existing carbon intensity-FDI nexus. Since the beginning of the twenty-first century, with an increasing number of middleand low-income countries participating in the global value chain and production, an increasing number of multinational companies began to set up a production branch in developing countries. However, there is little research on the effect of FDI on the environment of different kinds of countries. To date, only Perkins and Neumayer (2009) used the dynamic spatial model to investigate the influence of three broad and widely discussed transnational linkages created by international trade, inward FDI and telecommunications 
on domestic pollution efficiency in developing countries. However, their sample includes only the developing countries. Therefore, to close the gap in the existing research after analyzing the global carbon intensity trends, this paper first uses the panel data of 190 countries during 1990-2013 to analyze the effect of FDI on carbon intensity in different countries with different income levels separately.

The remainder of this paper is organized as follows: Section 2 presents the literature review. Section 3 describes carbon intensity in different regions. Section 4 presents the model and data description. Section 5 presents the empirical results. Section 6 provides conclusions and suggestions.

\section{Literature review}

In recent years, researchers have begun to focus on the causes and mechanisms of environmental pollution, and the relationship between capital flow and the environment as one of the most controversial issues. To reduce the implementation costs and fees leading to higher environmental standards, the enterprises in developed countries tend to transfer the pollution industry through FDI to the developing countries with low environmental control standards, which significantly worsens the host country's environment. This is the classical "pollution haven hypothesis" proposed by Chichilnisky (1994) and Copeland and Taylor (1994). Copeland and Taylor (1994) propose a static model of North-South trade to examine linkages between national income, environmental quality and international trade. One of the most important results from their study is that the income gains arising from an opportunity to trade can affect pollution in a different way from the income gains obtained through economic growth. By isolating the scale, composition and technique effects of international trade on pollution, they show that free trade increases world pollution: if the human-capitalpoor country is less densely populated than the rich country, then its tendency to specialize in pollution-intensive goods will be reinforced.

Several studies find that the pollution halo hypothesis exists, as multinational companies with advanced technology and management may face strict environmental standards and requirements in the host country (Dean, 1992; Zarsky, 1999). Thus, if multinational corporations invest in host countries, on the one hand, they tend to improve their efficiency in the use of resources to solve environmental pollution problems of domestic enterprises in the host countries, whereas, on the other hand, they promote the development of the host countries' environmental protection technology via knowledge diffusion, technology spillover, transfer of funds and other ways. The transnational corporations (TNCs)' investment promotes the host country's economic development and technological progress, and helps the country to reduce its environmental issues.

In fact, the relationship between FDI and pollution levels could take various and opposing shapes. Many scholars try to verify this hypothesis by using different samples and data. Their findings can be divided into four categories. The first category comprises several studies which find that FDI reduces the carbon emissions of the host country. Birdsall and Wheeler (1993) found that openness actually encourages a cleaner industry by eliminating barriers to importation of an industrialized country's pollution standards, while protected economies are more likely to favor pollution-intensive industries. Wheeler (2001) used the data of three developing countries receiving the most FDI to study their pollution trend: China, Brazil and Mexico. The results show that their pollution levels decrease with an increase in FDI. Perkins and Neumayer (2008) tested the relationship between 114 countries and their $\mathrm{FDI}$ and $\mathrm{CO}_{2}$ and $\mathrm{SO}_{2}$ emission efficiency. The result shows that the "dirtier" economies improve their environment efficiency faster when they adopt environmentally sound technologies and policies similar to those in "cleaner" countries, resulting in catch-up

\section{Does FDI affect carbon intensity?}


IJCCSM

10,1

and convergence over time. Atici (2012) found that FDI has a small negative but significant effect, indicating that FDI does not tend to increase pollution levels in the region. And, FDI has an alleviating impact on the groups of developed countries, suggesting that FDI invests primarily in non-polluting sectors of these countries. Zeng and Eastin (2012) examined the environmental effects of FDI from less developed countries (LDCs). They found that rather than transferring poor home-country practices across borders, FDI of LDCs can increase the level of environmental stewardship of host-country firms. Asghari (2013) tested the validity of pollution haven and halo pollution hypotheses in the context of FDI by analyzing the correlation between carbon emissions and FDI inflow of seven Middle Eastern and North African (MENA) countries during the period of 1980-2011. The results show that FDI inflow has a weak and statistically significant negative relationship with $\mathrm{CO}_{2}$ emission, which suggests weak support for the halo pollution hypothesis. Zhu et al. (2016) indicated that the effect of FDI on carbon emissions is negative in the middle- and high-emissions countries of the Association of South East Asian Nations (ASEAN), which supports the halo effect hypothesis.

The second kind of finding is the existence of a "pollution haven". Several studies found that FDI significantly increases carbon emissions of the host country, which supports the pollution haven hypothesis. Javorcik and Wei (2001) found some support for the "pollution haven" hypothesis after taking into account the level of corruption in host countries and using a firm-level data set on investment projects in 24 transition economies. They found that the investment from pollution-intensive multinational firms as a share of total inward FDI is smaller for host countries with a higher environmental standard. However, support for the "pollution haven" hypothesis is not immune to various sensitivity checks. Xing and Kolstad (2002) evaluated the effect of stringent environmental policies on the location choice of polluting industries. Their study postulated that developing countries may utilize lenient environmental regulations as a strategy to compete for the investment of polluting industry from developed countries. This provides indirect support of the "pollution haven" hypothesis. Pollution-intensive industries experience a significant effect from the strictness of environmental regulations on FDI. Grimes and Kentor (2003) examined the impact of FDI on $\mathrm{CO}_{2}$ during 1980-1996 in $66 \mathrm{LDCs}$. They found that FDI in LDCs is concentrated in the energy-consuming industries, and the foreign capital penetration in 1980 had a significant positive effect on the countries' $\mathrm{CO}_{2}$ emissions growth. Hoffmann et al. (2005) used the panel data of 112 countries to test whether FDI is a Granger causality of $\mathrm{CO}_{2}$ emission. They found that only for middle-income countries, inward FDI Granger-causes $\mathrm{CO}_{2}$ emissions, and in low-income countries, $\mathrm{CO}_{2}$ Granger-causes inward FDI flows. Thus, the pollution haven hypothesis is corroborated only with respect to low-income countries. The reason for this is that in the absence of FDI-attracting factors such as infrastructure and skilled labor, lowincome countries may use lax environmental regulations to compete in the FDI tournament, and the "innocent" pollution havens may emerge when low-income countries cannot afford the costs of implementing and monitoring environmental regulations. Jorgenson (2007) investigated the extent to which the transnational organization of production in the context of foreign investment dependence affects the environment in LDCs. The panel regression result indicated that foreign investment dependence in manufacturing was positively associated with total $\mathrm{CO}_{2}$ in $37 \mathrm{LDCs}$ during 1975-2000, and the emission of organic water pollutants in 29 LDCs during 1980-2000. Acharyya (2009) examined the growth impact of $\mathrm{FDI}$, and the FDI-induced growth impact on $\mathrm{CO}_{2}$ emissions using data from India during 1980-2003. They found that the long-run growth impact of $\mathrm{FDI}$ inflow on $\mathrm{CO}_{2}$ emissions is quite large. Using the data from 1981 through 2010 on $\mathrm{CO}_{2}$ emissions, income, energy 
consumption and inward FDI in five ASEAN countries, Baek (2016) provides evidence that FDI has a detrimental effect, giving support to the pollution haven hypothesis.

The third kind of result is the finding that the "pollution haven hypothesis" is not significant in practice. For example, Zarsky (1999) found that "pollution havens" cannot be proven. As the local and national regulations can be effective, there is a great need for an overarching global framework to heighten investor environmental responsibilities and get out of being "stuck in the mud". Elliott and Shimamoto (2008) investigated Japanese outbound FDI to three of its closest neighbors: Malaysia, Indonesia and the Philippines, and their study results did not support the pollution haven hypothesis. Kirkpatrick and Shimamoto (2008) tested the pollution haven hypothesis using data on Japanese inward FDI in five dirty industries: the iron and steel industry, the nonferrous metals industry, the chemicals industry, the paper and pulp industry and the nonmetallic products industry. Their study does not support the pollution hypothesis. On the contrary, they find that Japanese inward FDI appears to be attracted to countries that have transparent and stable environmental regulations, suggesting that certainty and transparency of the regulatory framework have a higher influence on foreign investors' location choice than the relative level of environmental regulation. Perkins and Neumayer (2009) used the $\mathrm{CO}_{2}$ efficiency data of 98 countries through the years 1980-2005 and the $\mathrm{SO}_{2}$ efficiency data of 92 countries through the years 1980-2000 to test whether developing countries' linkages with more $\mathrm{CO}_{2}$ and $\mathrm{SO}_{2}$-efficient economies contribute to domestic improvements in $\mathrm{CO}_{2}$ and $\mathrm{SO}_{2}$ efficiency. They found that inward FDI stocks do not appear to act as conduits for cross-border spillovers of environmental efficiency.

The fourth kind of result is the finding that the "pollution haven hypothesis" and the "pollution halo hypothesis" are both supported. Pao and Tsai (2011) found a strong bidirectional Granger causality between emissions and FDI, which implies that emissions and FDI are jointly determined and affected. With respect to the emissions/FDI direction, it seems to support the pollution haven. With respect to the FDI/emissions direction, it seems to support both the halo effect and the scale effect. Shahbaz et al. (2016) investigated the causal relationship between $\mathrm{FDI}$, economic growth and $\mathrm{CO}_{2}$ emissions using the data from 117 countries over the period of 1985-2010. Using panel unit root tests, panel cointegration analysis, homogenous causality tests and heterogeneous causality tests, they found a bidirectional causality relationship between FDI and $\mathrm{CO}_{2}$ emissions in some high-income, middle-income and low-income countries.

\section{Carbon intensity analysis}

Carbon intensity can be calculated as the ratio of $\mathrm{CO}_{2}$ and GDP in a certain period. Figure 1 shows carbon intensity of nine high-income countries, namely, the United Arab Emirates, Australia, Canada, Germany, the UK, Italy, Japan, the Republic of Kore, and the USA during 1990 through 2013. Figure 1 shows that most of the countries' carbon intensities reduced, and only Italy and Japan's carbon intensity did not change dramatically. In the nine countries, the USA had the highest carbon intensity, and Italy's emission intensity was the lowest during most times. Through the development of strict regulation, low energy consumption, industrial structure and other measures, the high-income countries' carbon intensity decreased slowly; it is worth mentioning that the USA's carbon intensity decreased rapidly. The implementation of strong environmental policies will help a country to reduce its carbon intensity (Ponce de Leon Barido and Marshall, 2014).

Figure 2 shows carbon intensity of representative middle- and low-income countries, namely, Brazil, China, India, Kazakhstan, Mexico, the Philippines, Romania, Vietnam and South Africa. While most of the developing countries' carbon intensity decreased over time,
Does FDI
affect carbon
intensity?

31 


\section{IJCCSM}

10,1

\section{2}

Figure 1.

Carbon intensity trends in representative highincome countries (1990-2013)
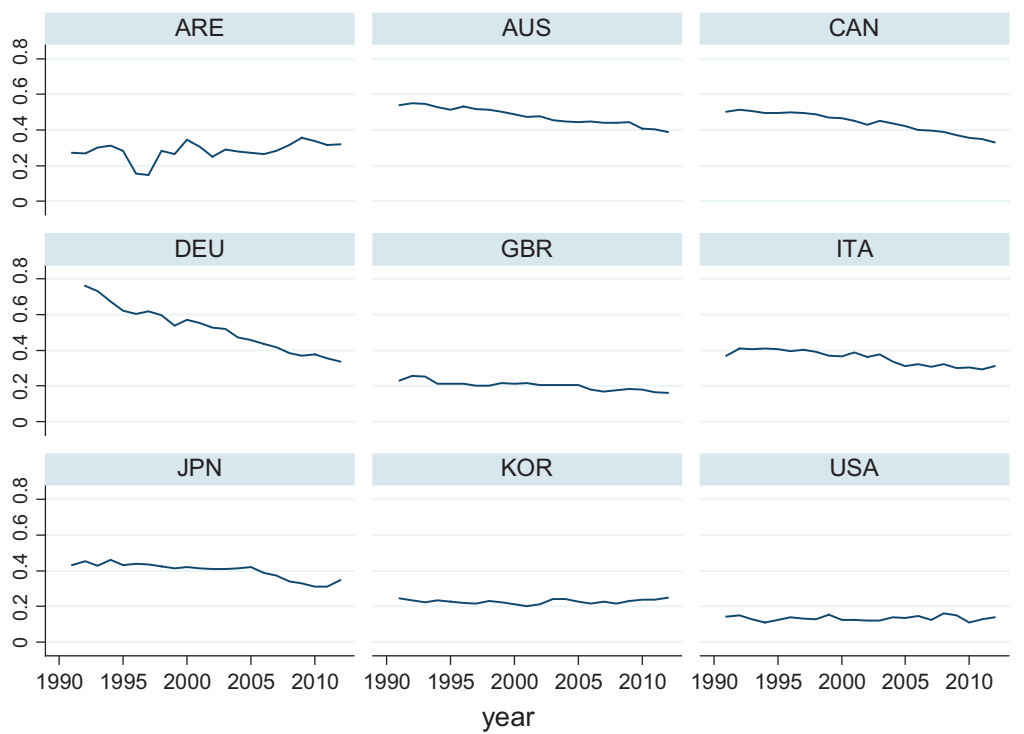

KOR
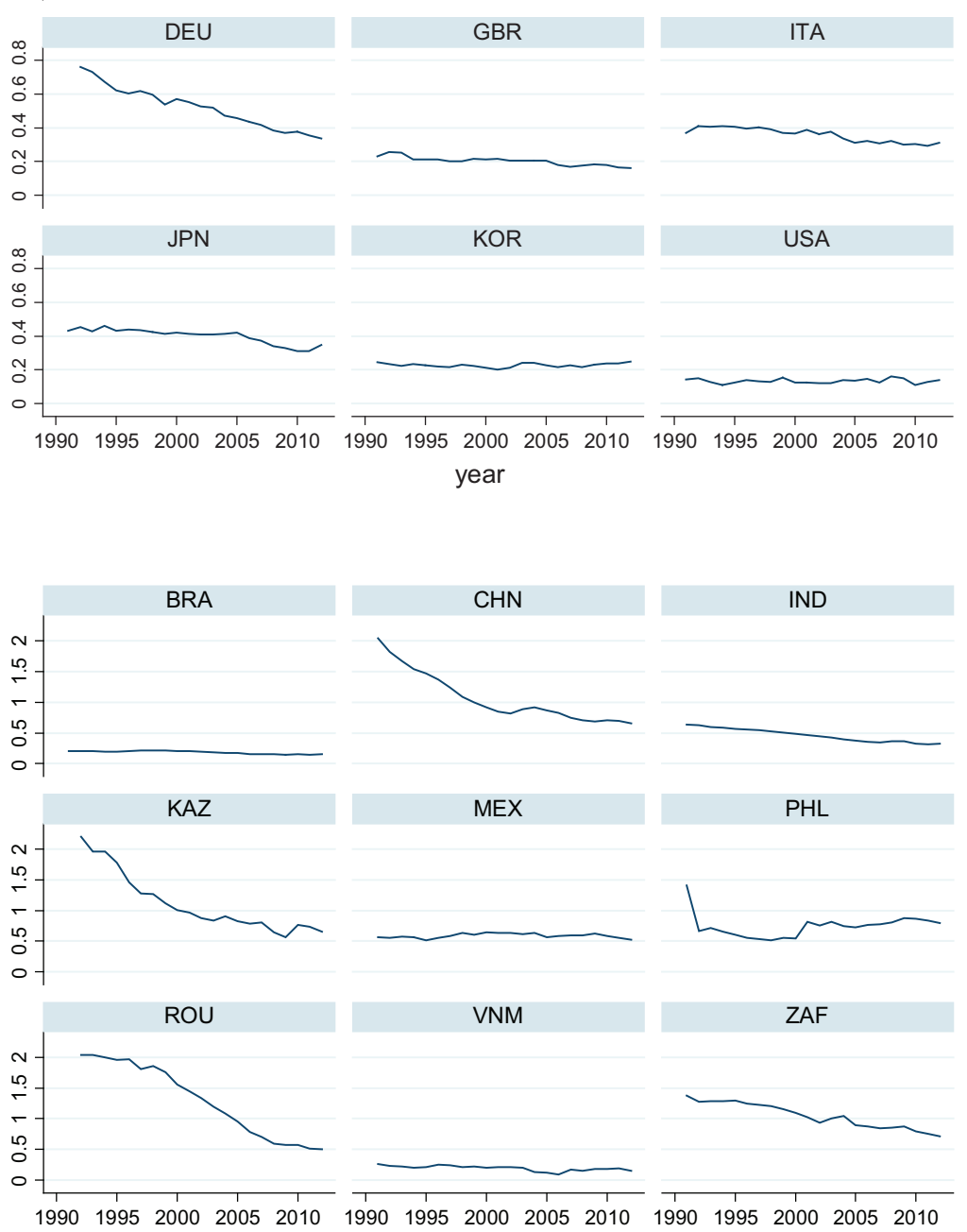

VNM

ZAF

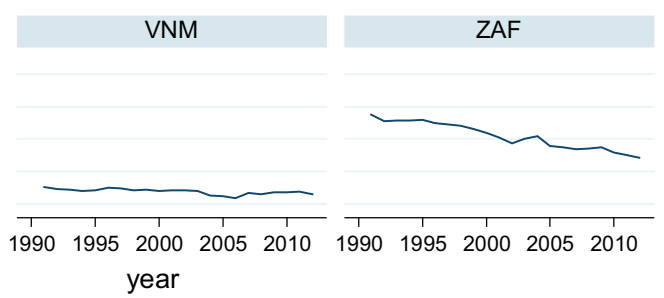

AUS

CAN

ITA

USA
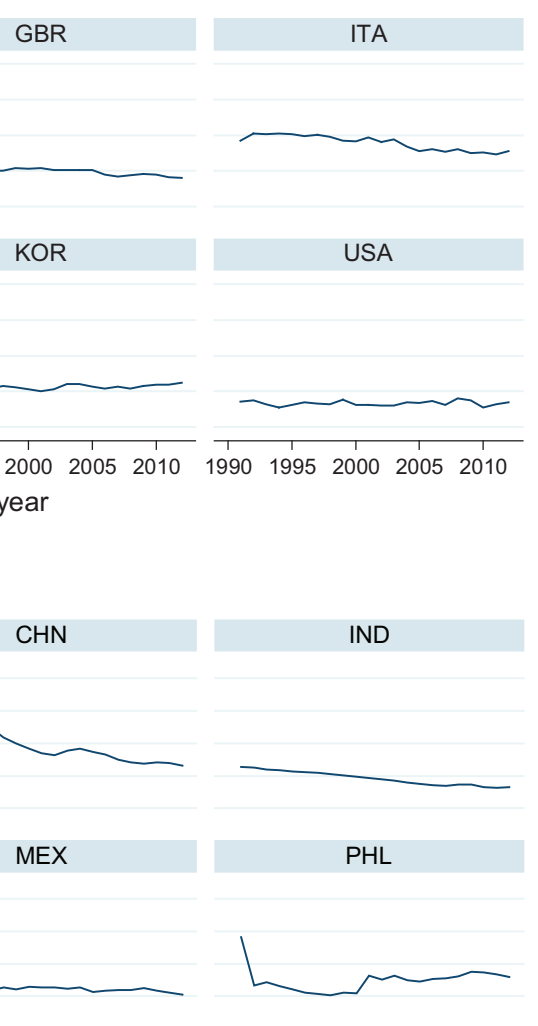

Figure 2.

Carbon intensity trends in representative middle- and lowincome countries (1990-2013)

. 
Agreement on the global energy saving and emission reduction, carbon intensity emissions in most middle- and low-income countries have decreased significantly, mainly through the reduction of high-energy-consuming industries, the use of advanced technology and so on (Pao and Tsai, 2011).

Figures 3 and 4 show the average carbon intensity of high-income countries and middleand low-income countries during 1990-2013. The countries for the high-income countries and middle and low-income countries are show in the Appendix. Both countries show similar fluctuation characteristics with downward trends. The reason for this might be that these countries enforce a stronger environmental policy, which has a more beneficial (or, a less negative) impact on emissions (Poumanyvong et al., 2012).

\section{Econometric methodology and data description}

\subsection{The variables and data description}

Based on previous studies, the variables and data are described.

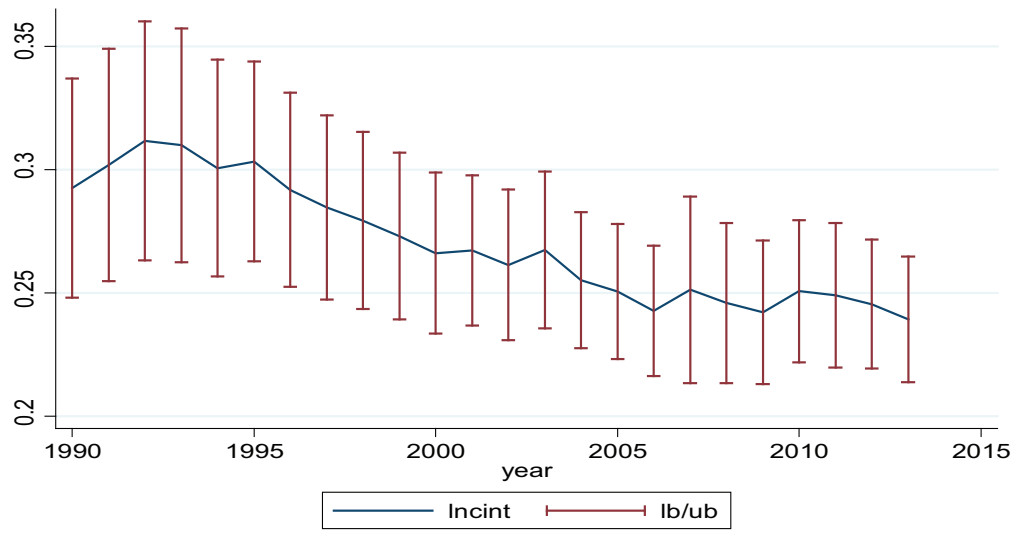

Figure 3.

Average carbon intensity trends in

high-income countries

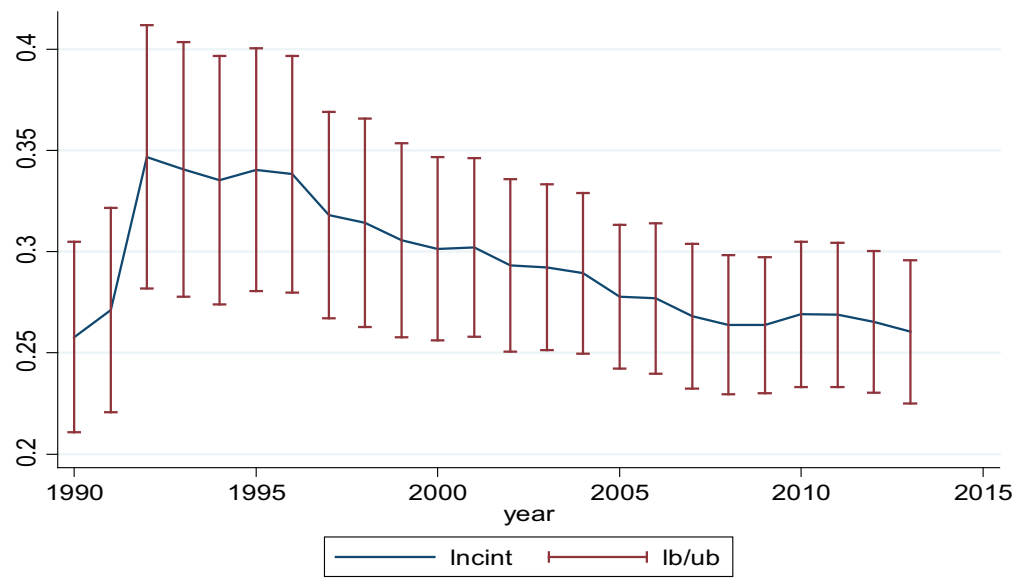

Figure 4 .

Average carbon intensity trends in middle- and lowincome countries 
IJCCSM

10,1

\subsubsection{Dependent variable}

4.1.1.1 Carbon intensity (cint). According to the definition, carbon intensity of a country/ region can be measured by its actual $\mathrm{CO}_{2}$ emissions divided by GDP. The country's carbon intensity depends not only on the technical level but also on industrial intensity, the process of industrialization, the share of fossil fuels in total energy consumption, FDI and other economic factors. This paper will discuss these factors in the following text.

4.1.2 Explanatory variables

4.1.2.1 Foreign direct investment (fdi). The effect of FDI on carbon intensity is uncertain. If FDI inflow promotes the development of cleaner technologies and productions, which supports the halo hypothesis, a negative sign for this variable can be expected. However, if FDI inflow induces the increase in pollution, it will support the pollution haven hypothesis. To analyze the impact of FDI, this paper uses the proxy variable of the host country FDI to the GDP proxy variable. According to the previous analysis, the expected sign of the coefficients of the variable is uncertain.

4.1.3 Control variables. To control the effect on the other factors, it is best to isolate the influence of structural differences and therefore reduce the likelihood of generating spurious findings (Asghari, 2013; Perkins and Neumayer, 2009; Zhu et al., 2016).

4.1.3.1 Share of fossil fuels (foss). The carbon emission of fossil fuels is higher than that of non-fossil energy (Perkins and Neumayer, 2012). If a firm uses the same quantity of energy with a higher share of fossil fuels, it tends to produce a higher proportion of carbon emissions. This paper uses the share of fossil fuels to represent the variable, which is calculated using the fossil fuel consumption's proportion on total energy consumption. Therefore, the expected sign of the share of the coefficient is positive.

4.1.3.2 Industrial intensity (ind). All else remaining equal, the industry-intensive economies are often less $\mathrm{CO}_{2}$-efficient (Perkins and Neumayer, 2012). Industrial structure is expressed using the industrial added value to GDP in this paper. Therefore, the country's industrial intensity is positively associated with the country's carbon intensity.

4.1.3.3 Urbanization rate (urb). On the one hand, the level of development and urbanization is associated with higher carbon intensity, as is the percentage of urban population with access to improved water and sanitation; on the other hand, urban slum prevalence is associated with lower carbon intensity (Givens, 2015). This paper uses the ratio of the urban population to the total population to represent the factor. The effect of this indicator on carbon intensity is uncertain.

4.1.3.4 Trade openness (tragdp). The environmental impacts of trade liberalization in any country will depend not only on the effect of policy change on the overall scale of economic activity but also on the induced changes in the intersectoral composition of economic activity and in the technologies that are used to produce goods and services (Grossman and Krueger, 1991). This paper uses the proportion of import and export trade in GDP to stand for the effect of trade openness. The effect of this indicator on carbon intensity is uncertain.

In this paper, the data of the explained variable and explanatory variables are derived from the World Bank's World Development Indicator (WDI) database. The unit of carbon intensity is $\mathrm{kg}$ per GDP (constant 2011 PPP \$). The unit for the rest of the variables is per cent. This paper's country classification is in accordance with the World Bank's per capita national income. A high-income economy is defined by the World Bank as a country with a gross national income per capita above US\$12,475 in 2015, calculated using the Atlas method. The countries with per capita income below $\$ 12,475$ are deemed as the medium- to low-income groups. After excluding the nations with missing data, the high- and medium- to 
low-income groups finally obtained were 63 and 125 countries, respectively. Among them, China is categorized in the medium- to low-income countries.

All the data were transformed into natural logarithms. The descriptive statistics for the variables used are displayed in Table I.

Table II presents the correlation matrix, where all the correlation coefficients between the variables are less than 0.7 . Table II shows that all the factors except FDI are significantly positively correlated with carbon intensity. The variance inflation factor (VIF) test result is lower than 10, which indicates that there are no general problems with the data.

\subsection{The model}

As the regional per capita carbon intensity adjustment process is relatively slow, the current emissions may depend on past emissions. Therefore, to prevent the basic measurement mode set bias, this paper introduces the dependent variable hysteresis in the regression model. The discussion suggests the following log-linear dynamic panel data model:

$$
\begin{aligned}
\text { lncint }_{i, t}= & \beta_{1} \text { lncint }_{i, t-1}+\alpha_{1} \operatorname{lnfdi}_{i, t}+\alpha_{2} \text { lnfoss }_{i, t}+\alpha_{3} \operatorname{lnind}_{i, t}+\alpha_{4} \text { lnurb }_{i, t}+\alpha_{5} \operatorname{lntragd}_{i, t} \\
& +\mu_{i}+\varepsilon_{i, t}
\end{aligned}
$$

An important feature of the model is that the explanatory variable contains the lagged term of the explanatory variable. In addition, there is an important hypothesis that there is no sequence correlation for $\varepsilon_{i, t}$ in the model. The model is suitable for the estimation of panel data with a large cross section and a small order. Therefore, it is suitable for the panel data used in this paper. The advantage of the dynamic model is that when some explanatory variables are in the model, the endogenous errors of the model can be eliminated using the dynamic panel data measurement method, and consistency estimates of these explanatory

\begin{tabular}{|c|c|c|c|c|c|c|c|}
\hline & lncint & $\operatorname{lnfdi}$ & $\operatorname{lnfoss}$ & lnind & lnurb & lntragdp & \\
\hline Mean & -1.480 & 0.284 & 4.048 & 3.253 & 3.732 & 4.170 & \\
\hline SD & 0.676 & 1.818 & 0.719 & 0.479 & 0.674 & 0.671 & Table I. \\
\hline Minimum & -5.301 & -12.509 & 0.503 & 0.929 & 0.731 & -3.863 & Descriptive statistics \\
\hline Maximum & 0.760 & 6.145 & 4.605 & 5.365 & 4.605 & 6.276 & of variables \\
\hline
\end{tabular}
variable coefficients can be obtained.

\begin{tabular}{lclllll}
\hline & lncint & lnfdi & lnfoss & lnind & lnurb & lntragdp \\
\hline lncint & 1 & & & & & \\
lnfdi & -0.0781 & 1 & & & & \\
lnfoss & $0.1538^{*}$ & 0.0271 & 1 & & & \\
lnind & $0.1004^{*}$ & 0.0017 & $0.4503^{*}$ & 1 & & \\
lnurb & $0.1702^{*}$ & $0.1424^{*}$ & $0.6344^{*}$ & $0.4053^{*}$ & 1 & \\
lntragdp & $0.0959^{*}$ & $0.3091^{*}$ & $0.1508^{*}$ & $0.1344^{*}$ & $0.2283^{*}$ & 1
\end{tabular}

Note: $*$ Indicates that the coefficient is significant at the $5 \%$ level

Table II.

The correlation matrix of the variables 
IJCCSM

10,1

\section{6}

Anticipating that the effect of FDI on carbon intensity would be different from different regions, this paper fits the model to the entire sample, with the subsample comprising highincome countries and middle- and low-income countries. The corresponding correlation matrix for the samples shows that the correlation coefficients are less than 0.7. This means there is no obvious multicollinearity problem in the regression.

\section{Empirical results}

\subsection{Result with worldwide samples}

This paper estimates the dynamic panel data model using the difference GMM method, see Table III for the results with all the samples. The Sargan test and the second-order sequence correlation test $(\mathrm{AR}(2))$ cannot reject the null hypothesis, indicating that there is no significant sequence correlation in the interference term of the GMM estimation model, and the selection of the instrument variable is reasonable.

Table III shows the estimation results with worldwide samples. Column 2 in Table III shows the result after considering the first-order lag of the dependent variable only. The result shows that the lag dependent variable (l.ncint) has a positive and statistically significant effect on the levels of domestic carbon intensity, which is in line with the expectation. Column 3 in Table III shows the estimation results after including FDI. The results show that the coefficient of FDI is significantly negative, indicating that FDI will reduce carbon intensity of the host country, which supports the halo effect hypothesis. The foreign companies often use improved environmental management practices and bring cleaner environmental technology to host country, which help the host country to reduce their carbon intensity (Asghari, 2013; Perkins and Neumayer, 2008; Zarsky, 1999). FDI may be more sensitive to environmental regulations than the other proxies, and the environmental governance of foreign enterprises will be higher than domestic business resources, which are conducive to the improvement of the environment of a country (Dijkstra and De Vries, 2006; Eskeland and Harrison, 1997; Xing and Kolstad, 2002). As the generators, owners and users of many of the world's most advanced technologies, TNCs can deploy these for competitive advantage in host economies; thus, more modern environmental efficiency technologies are transferred to host economies directly through investments in subsidiaries, joint ventures and affiliates, in turn accelerating the

\begin{tabular}{lccc}
\hline & Model $(1)$ & Model $(2)$ & Model $(3)$ \\
\hline 1. Incint & $0.825^{* * * *}(0.0001)$ & $0.716^{* * * * *}(0.0010)$ & $0.676^{* * * *}(0.0039)$ \\
lnfdi & & $-0.008^{* * * *}(0.0001)$ & $-0.011^{* * * * *}(0.0004)$ \\
lnfoss & & & $0.138^{* * * *}(0.0076)$ \\
lnind & & & $0.017^{* * * *}(0.0045)$ \\
lnurb & & $-0.331^{1 * * *}(0.0094)$ \\
lntragdp & $-0.265^{* * * *}$ & $-0.414^{* * * *}$ & $-0.052^{* * *}(0.0014)$ \\
Constant & -0.0002 & -0.0022 & $0.485^{* * * *}$ \\
& 4,112 & 3,352 & -0.0241 \\
Number of observations & 188 & 173 & 2,098 \\
Number of instruments & 1.0000 & 1.0000 & 116 \\
Sargan $p$-value & 0.0000 & 0.0000 & 1.0000 \\
AR(1) $p$-value & 0.4413 & 0.9893 & 0.0000 \\
AR(2) $p$-value & & & 0.4482 \\
\end{tabular}

Table III.

The regression result with all the samples
Notes: Standard errors are in parentheses; $* * *$ indicate that the coefficient is significant at the $1 \%$ level, respectively 
international spread of carbon reduction innovation (Perkins and Neumayer, 2008). Therefore, the transfers of production will reduce worldwide pollution (Copeland and Taylor, 1994).

After including the share of fossil fuels, industrial intensity, urbanization level and trade openness in Model (3), it is seen that the impact of FDI is still significantly negative, which verifies the stability and reliability of the model results. For the control variables shown in Model (3) in Table III, it can be seen that the coefficients of the ratio of fossil fuels and industrial intensity are both significant with the expected sign. This is in line with the finding of Perkins and Neumayer (2012), which states that the domestic share of fossil fuel consumption ratio and industry intensity are both negatively related with a country's $\mathrm{CO}_{2}$ efficiency. Urbanization level has a significantly positive effect, which is consistent with the finding of Poumanyvong et al. (2012) and Ponce de Leon Barido and Marshall (2014). Trade openness significantly reduces carbon intensity, which is in line with the finding of Rafiq et al. (2016). The reason for this might be that increased trade openness facilitates the transfer of cleaner and more energy-efficient technology in the countries.

\subsection{Result using the sample of high-income countries}

As discussed in Section 3, as a result of the development of different countries, there may be some characteristic differences for the relationship between a country's FDI and carbon intensity. To further test whether different countries display significant differences in the impact of FDI on carbon intensity, this paper divides the sample into high-income countries and middle- and low-income counties. The results are shown in Table IV and Table V, respectively.

The result in Column 2 of Table IV indicates that the lag dependent variable (1.lncint) has a positive and statistically significant effect on the levels of domestic carbon intensity of high-income countries. The results of Models (5)-(6) in Table IV show that FDI of highincome countries has a significantly negative effect on their carbon intensity, indicating that FDI will significantly reduce carbon intensity of high-income countries, supporting the halo effect hypothesis. The main reason is that the higher-income country chooses stronger environmental protection and specializes in relatively clean goods (Copeland and Taylor, 1994). The majority of FDI originates in developed economies, where levels of technical

Notes: Standard errors are in parentheses; ***indicate that the coefficient is significant at the $1 \%$ level, respectively

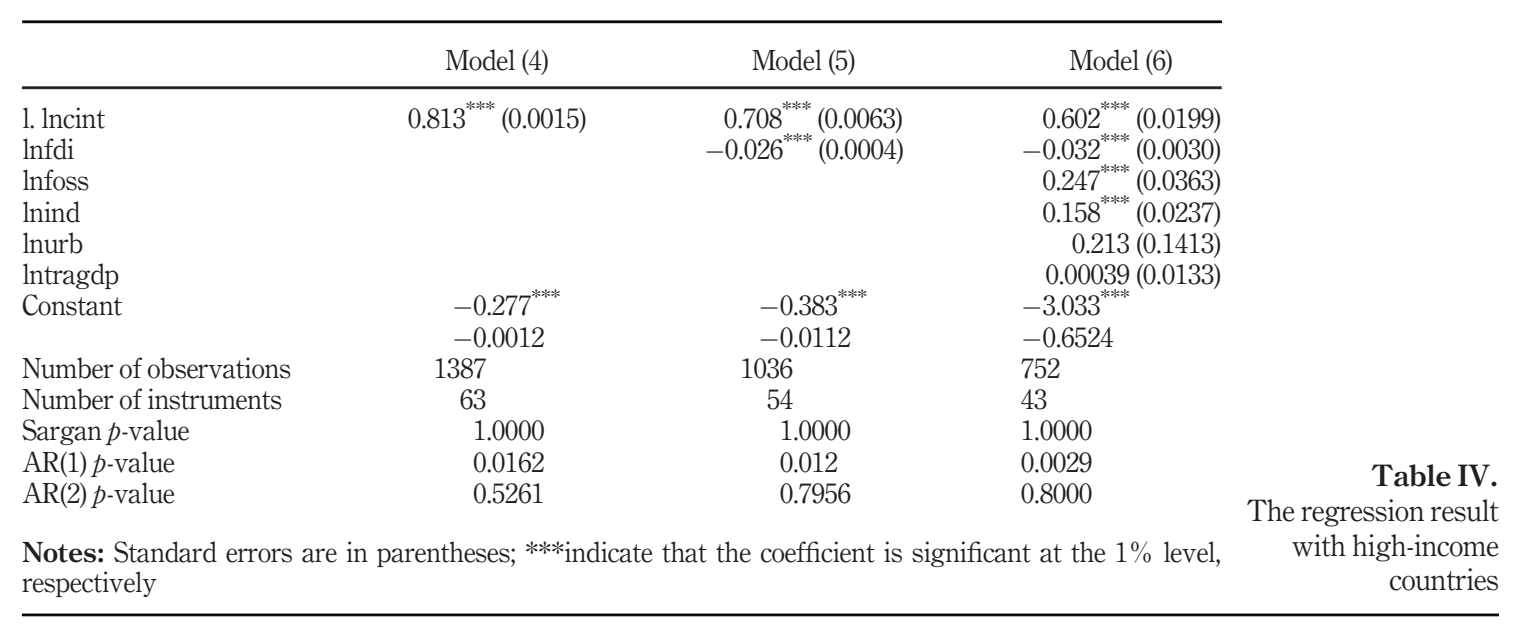

\section{Does FDI affect carbon intensity?}




\begin{tabular}{|c|c|c|c|c|}
\hline $\begin{array}{l}\text { IJCCSM } \\
10,1\end{array}$ & & Model (7) & Model (8) & Model (9) \\
\hline 38 & $\begin{array}{l}\text { 1. Incint } \\
\text { lnfdi } \\
\text { lnfoss } \\
\text { lnind } \\
\text { lnurb } \\
\text { lntragdp }\end{array}$ & $0.789^{* * * * *}(0.0031)$ & $\begin{array}{r}0.793^{\text {******* }}(0.0024) \\
-0.002^{\text {***** }}(0.0003)\end{array}$ & $\begin{array}{r}0.768^{* * * *}(0.0134) \\
-0.003^{* * * *}(0.0005) \\
0.102^{* * * *}(0.0122) \\
0.020^{* * * *}(0.0047) \\
-0.178^{* * * *}(0.0391) \\
-0.032^{* * * *}(0.0023)\end{array}$ \\
\hline & Constant & $\begin{array}{l}-0.321^{\text {*a* }} \\
-0.0055\end{array}$ & $\begin{array}{l}-0.315^{* 0.6} \\
-0.0045\end{array}$ & $\begin{array}{c}0.02 \\
-0.1139\end{array}$ \\
\hline & Number of observations & 2,725 & 2,316 & 1,346 \\
\hline & Number of instruments & 125 & 119 & 73 \\
\hline & Sargan $p$-value & 1.0000 & 1.0000 & 1.0000 \\
\hline & $\mathrm{AR}(1) p$-value & 0.0000 & 0.0000 & 0.0000 \\
\hline The regression result & $\operatorname{AR}(2) p$-value & 0.6113 & 0.8185 & 0.3977 \\
\hline
\end{tabular}

Notes: Standard errors are in parentheses; ***indicate that the coefficient is significant at the $1 \%$ level, respectively

efficiency and regulatory standards are invariably comparative, and FDI may generate environmentally beneficial technological spillovers, which might raise environment efficiency through competitive dynamics (Perkins and Neumayer, 2008). Furthermore, inward FDI of a developed country appears to be attracted by its transparent and stable regulatory environment, suggesting that the transparency regulatory of developed countries has a greater influence on foreign investors' choice of location (Kirkpatrick and Shimamoto, 2008). Another reason might be that FDI has an alleviating impact on carbon intensity of groups of developed countries, suggesting that FDI occurs primarily in non-polluting sectors in these countries (Atici, 2012). Overall, FDI benefits carbon intensity of high-income countries.

After including the share of fossil fuels, industrial intensity, urbanization level and trade openness in Model (6), it was found that the impact of FDI is still significantly negative. For the control variables shown in Model (6) in Table IV, it can be seen that the share of fossil fuels and industrial intensity both have a significant effect on carbon intensity with the expected sign. However, urbanization level and trade openness do not have a significant effect on carbon intensity of high-income countries.

\subsection{Result using the sample of middle-and low-income countries}

The results of Model (7) in Table V indicate that the lag dependent variable (1.lncint) has a statistically significant positive effect on carbon intensity of middle- and low-income countries. The results of Models (8)-(9) in Table V show that the effect of FDI on carbon intensity for middle- and low-income countries is negative, and it is significant at the 1 per cent level. Thus, their inward FDI affects their carbon intensity significantly. It means that middle- and low-income countries can obtain certain "technology spillover from FDI". The empirical results also indicate that the impact of FDI on carbon intensity is evidently homogenous for different countries. The late industrializing (i.e. developing) countries tend to adopt environmental policy measures at the levels as the industrialized (i.e. developed) economies did in the past (Hilton, 2001; Perkins and Neumayer, 2009). In particular, this result is in line with the finding of Talukdar and Meisner (2001), who found that there was a negative correlation between FDI and $\mathrm{CO}_{2}$ emissions using the panel data of 44 developing countries during the period of 1987-1995. It is necessary to point out that their dependent 
variable is $\mathrm{CO}_{2}$ emissions per capita. It is worth mentioning that this result is also consistent with the finding of Perkins and Neumayer (2008), who found that FDI has a positive and statistically significant impact on $\mathrm{CO}_{2}$ emissions efficiency in developing countries. Although those studies use a different period and dependent variables, they all verify the existence of halo pollution hypothesis.

The result indicates that TNCs are transferring environmental innovations to lowerincome countries, and FDI also has a significant environment-efficiency-enhancing effect for middle- and low-income countries (Perkins and Neumayer, 2012). Of course, it could be noted that the measure of FDI is too broad to capture the hypothesized substantive influence of TNCs, which is most likely to be using FDI in the context of pollution-intensive sectors. Unfortunately, there are no sectorally disaggregated bilateral FDI data with wide coverage (Perkins and Neumayer, 2009). This also indicates the research direction, and this thesis can be tested using industrial data.

After including the share of fossil fuels, industrial intensity, urbanization level and trade openness in Model (9), it was found that the impact of FDI is still insignificant. For the control variables shown in Model (9) in Table V, it can be seen that the share of fossil fuels and industrial intensity both have an expected effect on carbon intensity. Urbanization level has a significantly positive effect, which is consistent with the finding of Zhang et al. (2014). Trade openness significantly reduces carbon intensity, which is in line with the finding of Rafiq et al. (2016).

\section{Research conclusions and policy recommendations}

This paper first analyzes the effect of FDI on carbon intensity by using the data of 188 countries during 1990-2013. The dynamic panel data model is first used to consider the endogeneity problem, so that more reliable results can be obtained. The result shows that FDI has a significant negative impact on carbon intensity of the host country. After considering the share of fossil fuels, industrial intensity, urbanization level and trade openness, the impact of FDI on carbon intensity is still significantly positive. In addition, the share of fossil fuels and industrial intensity are both positively correlated with carbon intensity, while urbanization level and trade openness are both negatively correlated with carbon intensity. Furthermore, FDI also has a significant negative impact on carbon intensity of high-income countries and middle- and low-income countries. However, the effect of urbanization level and trade openness on high-income countries becomes insignificant, and the effect of other control variables is still significant with the expected sign.

This paper proposes policy recommendations.

First, the result shows that FDI spillovers have a negative effect on the reduction of carbon intensity in high-income countries. Therefore, the countries attracting FDI should focus on the introduction of high-tech content while formulating a strict environmental access system and preventing resource-intensive and pollution-intensive investment through modifying the catalog of attracting FDI and adjusting relative preferential policies. The economic development efforts of the country should not only consider the amount of FDI but should also pay attention to the quality of FDI and encourage enterprises to learn advanced technology of FDI companies through demonstration, competition, related personnel flow and absorption. In addition, relevant government departments should strengthen their supervision and management responsibilities and implement FDI policies to achieve low-carbon investment development.

Second, these countries should reduce the proportion of fossil fuel use as soon as possible. If a country wants to achieve a low-carbon energy structure, it is imperative to control the 
IJCCSM 10,1

rapid growth of coal production. From a production point of view, it is necessary to form a large coal enterprise group with the merger and reorganization of coal enterprises. From a consumption perspective, governments should facilitate the practice of "using the oil and gas first, using the coal last", to reduce the proportion of coal consumption. In addition, it is important to encourage the use of clean and renewable energy and make full use of nuclear energy, wind energy, solar energy, tidal energy and other new energy sources to establish a long-term development mechanism of renewable and clean energy development, promotion and application.

Third, the related countries should vigorously strive to optimize their industrial structure. The countries should adopt existing scientific research systems and science and technology policies and focus on the development and utilization of new technologies to enhance their industrial energy efficiency and reduce their carbon emission. The related government departments should raise the price of energy through energy taxes to encourage firms to apply high technologies to reduce their energy consumption in the industry. At the same time, the countries should increase investment in research and development of carbon reduction technology, zero-carbon technology and carbon capture and storage for energy use and make good use of these investments in the industry to decrease carbon intensity.

\section{References}

Acharyya, J. (2009), "FDI, growth and the environment: evidence from India on $\mathrm{CO}_{2}$ emission during the last two decades", Journal of Economic Development, Vol. 34, pp. 43-58.

Asghari, M. (2013), "Does FDI promote MENA region's environment quality? Pollution halo or pollution haven hypothesis", International Journal of Scientific Research in Environmental Sciences, Vol. 1 No. 6, pp. 92-100.

Atici, C. (2012), "Carbon emissions, trade liberalization, and the japan-ASEAN interaction: a group-wise examination", Journal of the Japanese and International Economies, Vol. 26 No. 1, pp. 167-178.

Birdsall, N. and Wheeler, D. (1993), "Trade policy and industrial pollution in Latin America: where are the pollution havens?", The Journal of Environment \& Development, Vol. 2 No. 1, pp. 137-149.

Chichilnisky, G. (1994), "North-South trade and the global environment", The American Economic Review, Vol. 84 No. 4, pp. 851-874.

Copeland, B.R. and Taylor, M.S. (1994), "North-south trade and the environment", The Quarterly Journal of Economics, Vol. 109 No. 3, pp. 755-787.

Dean, J.M. (1992), “Trade and the environment: a survey of the literature”, Policy Research Working Paper, Vol. 68, pp. 103-116.

Dijkstra, B.R. and De Vries, F.P. (2006), "Location choice by households and polluting firms: an evolutionary approach", European Economic Review, Vol. 50 No. 2, pp. 425-446.

Elliott, R.J. and Shimamoto, K. (2008), "Are ASEAN countries havens for Japanese pollution-intensive industry?”, The World Economy, Vol. 31 No. 2, pp. 236-254.

Eskeland, G.S. and Harrison, A.E. (1997), "Moving to greener pastures? Multinationals and the pollution haven hypothesis", Journal of Development Economics, Vol. 70 No. 1, pp. 1-23.

Givens, J.E. (2015), "Urbanization, slums, and the carbon intensity of well-being: implications for sustainable development”, Human Ecology Review, Vol. 22 No. 1, pp. 107-128.

Gray, K.R. (2002), "Foreign direct investment and environmental impacts-is the debate over?", Review of European Community and International Environmental Law, Vol. 11 No. 3, pp. 306-313.

Grimes, P. and Kentor, J. (2003), "Exporting the greenhouse: foreign capital penetration and CO? Emissions 1980 1996", Journal of World-Systems Research, Vol. 9 No. 2, pp. 261-275. 
Grossman, G.M. and Krueger, A.B. (1991), Environmental Impacts of a North American Free Trade Agreement, National Bureau of Economic Research.

Hilton, F.H. (2001), "Later abatement, faster abatement: evidence and explanations from the global phaseout of leaded gasoline", The Journal of Environment \& Development: A Review of International Policy, Vol. 10 No. 3, pp. 246-265.

Hoffmann, R., Lee, C.G., Ramasamy, B. and Yeung, M. (2005), "FDI and pollution: a granger causality test using panel data", Journal of International Development, Vol. 17 No. 3, pp. 311-317.

Javorcik, B.K.S. and Wei, S.-J. (2001), Pollution Havens and Foreign Direct Investment: Dirty Secret or Popular Myth?, World Bank, Development Research Group, Trade.

Jorgenson, A.K. (2007), "Does foreign investment harm the air we breathe and the water we drink? A cross-national study of carbon dioxide emissions and organic water pollution in less-developed countries, 1975 to 2000", Organization \& Environment, Vol. 20 No. 2, pp. 137-156.

Kentor, J. and Grimes, P. (2006), "Foreign investment dependence and the environment: a global perspective", in Jorgenson, A.K. and Kick, E. (Eds), Globalization and the Environment, Brill Academic Press, The Netherlands, pp. 61-78.

Kirkpatrick, C. and Shimamoto, K. (2008), "The effect of environmental regulation on the locational choice of Japanese foreign direct investment", Applied Economics, Vol. 40 No. 11, pp. 1399-1409.

Li, T., Wang, Y. and Zhao, D. (2016), "Environmental Kuznets curve in china: new evidence from dynamic panel analysis", Energy Policy, Vol. 91, pp. 138-147.

Pao, H.-T. and Tsai, C.-M. (2011), "Multivariate granger causality between CO 2 emissions, energy consumption, FDI (foreign direct investment) and GDP (gross domestic product): evidence from a panel of BRIC (Brazil, Russian federation, India, and China) countries", Energy, Vol. 36 No. 1, pp. 685-693.

Perkins, R. and Neumayer, E. (2008), "Fostering environment efficiency through transnational linkages? Trajectories of CO2 and SO2, 1980-2000", Environment and Planning A, Vol. 40 No. 12, pp. 2970-2989.

Perkins, R. and Neumayer, E. (2009), "Transnational linkages and the spillover of environmentefficiency into developing countries", Global Environmental Change, Vol. 19 No. 3, pp. 375-383.

Perkins, R. and Neumayer, E. (2012), "Do recipient country characteristics affect international spillovers of CO2-efficiency via trade and foreign direct investment?", Climatic Change, Vol. 112 No. 2, pp. 469-491.

Ponce de Leon Barido, D. and Marshall, J.D. (2014), "Relationship between urbanization and $\mathrm{CO}_{2}$ emissions depends on income level and policy”, Environmental Science \& Technology, Vol. 48 No. 7, pp. 3632-3639.

Poumanyvong, P., Kaneko, S. and Dhakal, S. (2012), "Impacts of urbanization on national transport and road energy use: evidence from low, middle and high income countries", Idec Dp2, Vol. 46, pp. 268-277.

Rafiq, S., Salim, R. and Nielsen, I. (2016), "Urbanization, openness, emissions, and energy intensity: a study of increasingly urbanized emerging economies”, Energy Economics, Vol. 56, pp. 20-28.

Shahbaz, M., Nasreen, S. and Ozturk, I. (2016), "FDI, growth and CO2 emissions relationship: evidence from high, middle and low income countries", Bulletin of Energy Economics (BEE), Vol. 4, pp. 54-69.

Talukdar, D. and Meisner, C.M. (2001), "Does the private sector help or hurt the environment? Evidence from carbon dioxide pollution in developing countries", World Development, Vol. 29 No. 5, pp. $827-840$.

Wheeler, D. (2001), "Racing to the bottom? Foreign investment and air pollution in developing countries", The Journal of Environment \& Development: A Review of International Policy, Vol. 10 No. 3, pp. 225-245.

Xing, Y. and Kolstad, C.D. (2002), "Do lax environmental regulations attract foreign investment?", Environmental and Resource Economics, Vol. 21 No. 1, pp. 1-22. 
IJCCSM

10,1

Zarsky, L. (1999), "Havens, halos and spaghetti: untangling the evidence about foreign direct investment and the environment", Foreign direct Investment and the Environment, Vol. 13, pp. $47-74$.

Zeng, K. and Eastin, J. (2012), "Do developing countries invest up? The environmental effects of foreign direct investment from less-developed countries", World Development, Vol. 40 No. 11, pp. 2221-2233.

Zhang, Y.-J., Liu, Z., Zhang, H. and Tan, T.-D. (2014), "The impact of economic growth, industrial structure and urbanization on carbon emission intensity in china", Natural Hazards, Vol. 73 No. 2, pp. 579-595.

Zhu, H., Duan, L., Guo, Y. and Yu, K. (2016), "The effects of FDI, economic growth and energy consumption on carbon emissions in ASEAN-5: evidence from panel quantile regression", Economic Modelling, Vol. 58, pp. 237-248.

\section{Appendix}

List of abbreviated country codes of the sample:

High-income countries (63)

AND, ARE, ATG, AUS, AUT, BEL, BHR, BHS, BMU, BRB, BRN, CAN, CHE, CHL, CUW, CZE, DEU, DNK, ESP, EST, FIN, FRA, FRO, GBR, GIB, GRC, GRL, GUM, HKG, HRV, HUN, IMN, ISL, ISR, ITA, JPN, KNA, KOR, KWT, LTU, LUX, LVA, MAC, MLT, NLD, NOR, NRU, NZL, OMN, POL, PRT, PYF, SAU, SGP, SMR, SVK, SVN, SWE, SXM, TTO, URY, USA, VGB.

\section{Middle- and low-income countries (125)}

AFG, AGO, ARG, ARM, AZE, BDI, BEN, BFA, BGD, BGR, BIH, BLR, BLZ, BOL, BRA, BTN, BWA, CAF, CHN, CIV, CMR, COD, COG, COL, COM, CPV, CRI, CUB, DJI, DMA, DOM, DZA, ECU, EGY, ERI, ETH, FJI, GAB, GEO, GHA, GMB, GNB, GNQ, GRD, HND, HTI, IDN, IRN, IRQ, JAM, JOR, KAZ, KEN, KGZ, KHM, KIR, KSV, LAO, LBN, LBR, LBY, LCA, LKA, LSO, MAR, MDA, MDG, MDV, MEX, MHL, MKD, MLI, MMR, MNE, MNG, MOZ, MRT, MUS, MWI, MYS, NAM, NER, NGA, NIC, NPL, PAK, PAN, PER, PHL, PLW, PNG, PRY, PSE, ROU, RUS, RWA, SDN, SEN, SLB, SLE, SLV, SSD, STP, SUR, SWZ, SYR, TGO, THA, TJK, TKM, TLS, TON, TUN, TUR, TUV, UGA, UKR, UZB, VCT, VEN, VUT, WSM, ZAF, ZMB, ZWE.

\section{About the author}

Yanmin Shao is an Associate Professor of Donlinks School of Economics and Management, University of Science and Technology Beijing and Academy of Mathematics and Systems Science, Chinese Academy of Sciences. She conducts interdisciplinary research to study the production efficiency of the economy, with a particular emphasis on industry production and outward foreign direct investment. Her work has appeared in flagship journals, including Journal of Cleaner Production; Technological Forecasting and Social Change; Resources, Conservation and Recycling; and Journal of Systems Science and Complexity. She has worked several times as a Senior Research Assistant in Hong Kong City University. She got her doctor degree from the Academy of Mathematics and Systems Science, Chinese Academy of Sciences, in 2010. Yanmin Shao can be contacted at: yanminshao@amss.ac.cn

For instructions on how to order reprints of this article, please visit our website: www.emeraldgrouppublishing.com/licensing/reprints.htm Or contact us for further details: permissions@emeraldinsight.com 